\title{
MENINGKATKAN PEMBELAJARAN TEKNIK SHOOTING DALAM PERMAINAN \\ SEPAKBOLA MENGGUNAKAN MODEL PEMBELAJARAN TEAM GAMES TOURNAMENT SISWA KELAS X IPS 2 SMA NEGERI 1 KABAWETAN.
}

\author{
Ramos Triyudho \\ Universitas Bengkulu \\ ramostriyudho2693@gmail.com \\ Syafrial \\ Universitas Bengkulu \\ Sugiyanto \\ Universitas Bengkulu
}

\begin{abstract}
Abstrak
Penelitian ini bertujuan untuk meningkatkan keterampilan teknik shooting dalam permainan sepakbola menggunakan model pembelajaran kooperatif team games tournament siswa kelas X IPS 2 SMA Negeri 1 Kabawetan Kepahiang. Penelitian ini adalah penelitian tindakan kelas (classroom action research) dan dilaksanakan dalam dua siklus. Subjek dalam penelitian ini yaitu siswa kelas IPS 2 SMA Negeri 1 Kabawetan Kepahiang dengan jumlah siswa sebanyak 32 siswa yang terdiri dari 19 siswa putra dan 13 siswa putri. Pada setiap siklus terdiri dari empat langkah yaitu: Perencanaan, Pelaksanaan, Observasi dan Refleksi. Data yang diperoleh kemudian dianalisis melalui tahapan pengumpulan data dan penarikan kesimpulan, dimana teknik yang digunakan untuk pengumpulan data diperoleh melalui tahapan observasi, tes dan dokumentasi pelaksanaan kegiatan. Berdasarkan dari hasil penelitian dapat ditarik kesimpulan bahwa melalu penerapan model pembelajaran Team Games Tournament dalam pembelajaran dapat meningkatkan hasil belajar keterampilan teknik shooting dalam sepakbola pada siswa kelas X IPS 2 SMA Negeri 1 Kabawetan Kepahiang. Dari hasil yang telah dianalisis diperoleh peningkatan hasil belajar yang signifikan dari pra siklus, siklus I dan siklus II. Pada pra siklus presentasi ketuntasan hasil belajar siswa hanya mencapai 40,62\% dan pada siklus I presentasi ketuntasan hasil belajar teknik shooting mencapai $71,87 \%$ dengan jumlah yang masuk dalam kategori tuntas sebanyak 23 siswa, sementara itu pada siklus II diperoleh presentasi ketuntasan $81,25 \%$ dengan jumlah yang dikategorikan tuntas sebanyak 26 siswa dari jumlah keseluruhan siswa 32 siswa.
\end{abstract}

Kata kunci: Shooting, sepakbola.

\begin{abstract}
This study aims to improve the skills of shooting techniques in the game of football using cooperative learning model team tournament teams class X IPS 2 SMA Negeri 1 Kabawetan Kepahiang. This research is a classroom action research and carried out in two cycles. Subjects in this study are students of IPS class 2 SMA Negeri 1 Kabawetan Kepahiang with the number of students as much as 32 students
\end{abstract}


consisting of 19 male students and 13 female students. Each cycle consists of four steps: Planning, Implementation, Observation and Reflection. The data obtained are then analyzed through the stages of data collection and conclusion, where the techniques used for data collection are obtained through the stages of observation, test and documentation of the implementation of activities. Based on the results of research can be concluded that through the implementation of learning models Team Games Tournament in learning can improve the results of learning skills shooting techniques in football in students of class X IPS 2 SMA Negeri 1 Kabawetan Kepahiang. From the results that have been analyzed obtained significant learning outcomes from pre cycle, cycle I and cycle II. In the pre cycle of presentation of the students' learning achievement reaches only $40.62 \%$ and in the first cycle presentation completeness of shooting technique learning achievement reaches $71.87 \%$ with the number included in the completeness category of 23 students, while in the second cycle obtained a presentation of mastery $81,25 \%$ with total categorized as 26 students from total students 32 students.

Keywords: Shooting, soccer.

\section{PENDAHULUAN}

Pendidikan

memanusiakan manusia atau upaya membantu manusia agar mampu mewujudkan diri sesuai dengan martabat kemanusiannya, oleh karena pendidikan berarti upaya membantu manusia. (Dinn Wahyudin, 2008:1.1). Menurut Sakun (2012:6) mengatakan bahwa pendidikan adalah usaha yang sadar, teratur dan sistematis didalam memberikan bimbingan atau bantuan kepada orang lain yang sedang berproses menuju kedewasaan didalam dan luar sekolah, berlangsung seumur hidup.

Perlu kita ketahui terkait bahwa pendidikan jasmani olahraga dan kesehatan merupakan bagian integral dari pendidikan secara keseluruhan, bertujuan untuk mengembangkan aspek kebugaran jasmani, keterampilan gerak, keterampilan berpikir kritis, keterampilan sosial, penalaran, stabilitas emosional, tindakan moral, aspek pola hidup sehat dan pengenalan lingkungan bersih melalui aktifitas jasmani, olahraga dan kesehatan terpilih yang direncanakan secara sistematis dalam rangka mencapai tujuan pendidikan nasional. (Rosdiani, 2013:142).

Salah satu aktifitas jasmani antara lain dalam bentuk permainan. Permainan adalah salah satu cabang olahraga, permainan itu dibagi menjadi dua yaitu permainan bola besar dan permainan bola kecil.Salah satu diantara permainan bola besar yaitu sepak bola.Permainan sepakbola merupakan permainan yang sangat menarik dan populer di lingkup pendidikan sekolah.

Dalam sepakbola, gol merupakan tujuan dalam permainan dan juga sekaligus merupakan saat yang paling dinantikan oleh para pemain dan juga penonton. Lebih dari $70 \%$ gol-gol yang terjadi berasal dari shooting atau tembakan ke arah gawang lawan, sehingga dapat dikatakan shooting merupakan salah satu teknik dasar dalam permainan sepak bola yang harus diajarkan kepada siswa sekolah agar dapat bermain sepak bola dengan baik. Shooting atau tembakan dapat dilakukan dengan hampir semua bagian kaki, akan tetapi secara teknis agar bola dapat ditendang dengan baik, shooting atau tembakan diusahakan 
menggunakan punggung kaki atau kura-kura kaki, sisi kaki bagian dalam, sisi kaki bagian luar, punggung kaki bagian dalam, dan punggung kaki bagian luar.Berdasarkan observasi peneliti di lapangan, yang dilakukan tanggal 2 Februari 2017 kemampuan teknik shooting siswa kelas $X$ IPS 2 SMA Negeri 1 Kabawetan Kepahiang belum baik atau masih sangat rendah. Kebanyakan siswa belum memahami teknik shooting yang benar. Dari 32 siswa kelas $X$ IPS 2 hanya 10 siswa atau hanya sekitar $31 \%$ dari jumlah siswa tersebut yang mampu melakukan teknik shooting dengan benar. Ini dapat diakibatkan kurangnya perhatian siswa pada waktu diberi penjelasan oleh guru.

Pada mata pelajaran PJOK siswa juga banyak langsung bermain setelah melakukan pemanasan, tanpa terlebih dahulu mempelajari teknik-teknik dasar dalam permainan sepakbola, khususnya teknik shooting. Agar siswa mampu melakukan shooting dengan baik dan benar, pendidik harus bisa menciptakan suasana pembelajaran yang menyenangkan agar penyampaian materi mengenai shooting dapat diperhatikan dengan seksama oleh siswa. Selain itu pendidik juga harus dapat memberikan pemahaman kepada siswa bahwa shooting atau tembakan yang baik juga sangat dipengaruhi oleh faktor-faktor non teknis seperti kekuatan tembakan, akurasi atau arah tembakan serta keyakinan untuk mencetak gol.Pada kenyataannya mayoritas siswa kelas X IPS 2 SMA Negeri 1 Kabawetan Kepahiang masih kesulitan dalam melakukan shooting dengan benar. Ada tembakan siswa yang tidak akurat, ada siswa yang tembakannya sangat lemah pelan, ada pula yang tembakannya tidak sampai ke jarak gawang.Banyak faktor yang menyebabkan siswa kelas $X$ IPS 2 SMA Negeri 1 Kabawetan Kepahiang belum bisa melakukan shooting, diantaranya pendidik langsung mengajarkan teknik dasar, termasuk shooting, tanpa sebelumnya bisa menciptakan suasana pembelajaran yang menyenangkan bagi siswa. Berdasarkan permasalahan yang telah dikemukakan diatas, maka peneliti mengambil judul "Meningkatkan Keterampilan Teknik Shooting Dalam Permainan Sepakbola Menggunakan Model Pembelajaran Kooperatif Team Games Tournament Pada Siswa Kelas X IPS 2 SMA Negeri 1 Kabawetan Kepahiang Tahun Pelajaran 2016/2017. Kurangnya pengetahuan siswa tentang bagaimana melakukan shooting yang benar.

$$
\text { Penjelasan tentang shooting }
$$
sepakbola masih membosankan siswa, sehingga siswa kurang antusias.Penerapan teori kurang maksimal, dan metode pembelajaran yang kurang menarik (monoton).penelitian ini peneliti batasi hanya pada meningkatkan keterampilan teknik shooting dalam permainan sepakbola dengan menggunakan model pembelajaran kooperatif Team Games Tournament pada siswa kelas X IPS 2 SMA Negeri 1 Kabawetan Kepahiang.

Penelitian ini dapat dirumuskan sebagai berikut: "Apakah dengan menggunakan model pembelajaran kooperatif tipe Team Games Tournament dapat meningkatkan keterampilan teknik shooting dalam permainan sepakbola pada siswa kelas X IPS 2 SMA Negeri 1 Kabawetan Kepahiang"? penelitian ini mempunyai tujuan untuk mengetahui : Peningkatan hasil belajar shooting dalam permainan sepakbola kelas $X$ IPS 2 SMA Negeri 1 Kabawetan Kepahiang melalui model pembelajaran kooperatif Team Game Tournament.

\section{METODE}

Jenis penelitian yang digunakan adalah penelitian tindakan kelas (PTK) atau 
classroom action research. (Winarni 2011:59) penelitian tindakan kelas adalah penelitian yang bersifat reflektif dengan melakukan tindakan-tindakan tertentu agar dapat memperbaiki dan atau meningkatkan kualitas proses dan hasil pembelajaran yang diselenggarakan secara profesional. Wardhani (2008:1.4) penelitian tindakan kelas adalah penelitian yang dilakukan oleh guru didalam kelasnya sendiri melalui refleksi diri, dengan tujuan untuk memperbaiki kinerjanya sebagai guru, sehingga hasil belajar siswa menjadi meningkat. Menurut Arikunto (2006:3) memandang bahwa penelitian tidakan kelas adalah suatu pencermatan terhadap kegiatan belajar yang berupa tindakan, yang disengaja dimunculkan dan terjadi dalam suatu kelas yang bersama. Jadi penelitian tindakan kelas ini adalah suatu penelitian yang merujuk ke sebuah kelas.

Subjek yang akan diteliti dalam Penelitian Tindakan Kelas ini adalah siswa kelas $X$ IPS 2 SMA Negeri 1 KabawetanKepahiang yang berjumlah 32 siswa yang terdiri dari 19 siswa laki-laki dan 13 siswa perempuan.Sesuai dengan maksud dan tujuan penelitian ini, maka dalam pengumpulan data terlebih dahulu dilakukan pengukuran teknik shooting Kaki Tumpu dan Kaki Ayun (Steady Leg Position): Kaki yang tidak menendang bola dinamakan kaki tumpu dan kaki yang menendang bola dinamakan kaki ayun. Untuk menghasilkan tembakan yang keras kaki tumpu di samping atau sedikit di depan bola dan ujung kaki tumpu mengarah ke sasaran. Pergelangan kaki ayun harus terkunci atau kaku pada saat mengenai bola.Bagian Bola: Bagian bola yang dikenakan oleh kaki ayun adalah bagian tengah bola. Laju bola akan sangat kencang dan terarah dengan baik apabila dapat mengenai tepat di titik tengah bola.Perkenaan Kaki dengan Bola (Impact):
Bagian kaki ayun yang mengenai bola harus pada punggung kaki penuh atau kura-kura kaki.Gerakan Lanjutan (Follow Through): Sebagai tindak lanjut gerakan menendang dan memberi hasil tendangan yang lebih keras, maka kaki ayun harus betul-betul optimal ke depan.

\section{HASIL DAN PEMBAHASAN}

\section{Hasil}

Sebelum melakukan tindakan, peneliti melakukan tes awal terlebih dahulu untuk mendapatkan subjek penelitian

\section{Tes awal}

Hasil dari tes awal yang dilaksanakan pada prasiklus, menunjukkan bahwa masih banyak siswa yang belum menguasai teknik shooting sepakbola. Secara umum siswa melakukan shooting hanya semaunya, ada yang memakai ujung kaki, ada yang tendangannya melenceng ke kiri dan ke kanan dan sebagainya. Hasil dari pelaksanaan tes awal sebelum diberikan perlakuan dapat kita hitung sebagai berikut; Siswa dengan nilai tuntas: 13 siswa. Siswa dengan nilai tidak tuntas: 19 siswa

\section{Siklus I}

Hasil dari tes pada siklus 1 yang telah dilaksanakan, menunjukkan bahwa ada peningkatan dari tes awal. Namun masih ada siswa yang belum menguasai teknik shooting sepakbola. Setelah diberi perlakuan kemampuan siswa menjadi lebih baik dari pada sebelum diberikan perlakuan pada tes pra siklus. Hasil dari pelaksanaan tes siklus 1 setelah diberikan perlakuan dapat kita hitung sebagai berikut : Siswa dengan nilai tuntas: 23 siswa, Siswa dengan nilai tidak tuntas: 9 siswa. Dari data tes siklus 1 diatas, sudah meningkat secara signifikan, secara keseluruhan meningkat menjadi 71, 87 \% siswa kelas sudah mendapatkan nilai yang baik dalam melakukan teknik shooting 
permainan sepakbola. Meskipun nilai siswa sudah meningkat secara klasikal namun nilai tersebut belum mencapai KKM mata pelajaran PJOK di sekolah, yaitu sebesar 75 .

\section{Siklus II}

Hasil dari pelaksanaan tes siklus 2 setelah diberikan perlakuan dapat kita hitung sebagai berikut : Siswa dengan nilai tuntas: 26 siswa, Siswa dengan nilai tidak tuntas: 6 siswa. Dari data tes siklus 2 di atas, sudah meningkat dari tes pada siklus 1 , secara keseluruhan meningkat menjadi 81, 25 \% siswa kelas sudah mendapatkan nilai yang baik dalam melakukan teknik shooting permainan sepakbola. Dari hasil yang didapat pada tes siklus 2 ini secara klasikal nilai tersebut telah mencapai KKM mata pelajaran PJOK di sekolah, yaitu sebesar 75.Dari hasil ini, penelitian tindakan kelas sudah mencapai tujuan dan harapan dari peneliti.Maka penelitian ini cukup sampai dengan siklus 2 saja.

\section{Pembahasan}

Berdasarkan prosedur penelitian tindakan kelas yang sudah dirancang dan dilaksanakan dengan sistematis, peneliti dapat mengumpulkan data penelitian yang mungkin dapat berupa informasi penting dari hasil penelitian. Penerapan model pembelajaran kooperatif tipe TGT pada pembelajaran teknik shooting dalam permainan sepakbola memberikan dampak positif kepada siswa. Dari prosesnya observasi awal hingga pelaksanaan pada siklus 2 terjadi peningkatan pada tiap pertemuannya.

Pada tes awal sebelum diberikan perlakuan atau belum diberikan materi serta praktek melakukan teknik shooting yang benar, hasil dari tes tersebut masih dalam kategori rendah secara klasikal. Secara keseluruhan siswa yang mendapatkan nilai dengan kategori baik hanya sebanyak 13 siswa atau dalam persentasenya sebesar 40,62\%. Kemudian pada pertemuan siklus 2 setelah diberikan materi teknik shooting sepakbola, kemampuan siswa menjadi meningkat, dengan siswa yang mendapatkan nilai dengan kategori baik sebanyak 23 siswa dengan persentase secara keseluruhan sebesar $\mathbf{7 1 , 8 7}$ \%. Darihasil tes pada siklus 1 walaupun mengalami peningkatan namun secara klasikal belum mencapai KKM mata pelajaran PJOK sebesar 75. Untuk itu penelitian dilanjutkan pada siklus 2 dengan perbaikan-perbaikan di pertemuan berikutnya.

Setelah diberikan contoh melakukan teknik shooting yang benar seta dengan menggunakan metode pembelajaran kooperatif tipe TGT kemampuan siswa dalam melakukan shooting meningkat dengan hasil tes pada siklus 2 sebanyak 26 siswa mendapatkan nilai dengan kriteria baik, dan secara persentase keseluruhan siswa pada kelas X IPS 2 ini sudah mencapai KKM yaitu sebesar 81,25 \%.Dari hasil nilai tes pada siklus 2 yang sudah mencapai tujuan dari pembelajaran, maka penelitian tindakan kelas diakhiri pada siklus 2 saja tidak dilanjutkan untuk siklus berikutnya.

\section{PENUTUP}

\section{Simpulan}

Seluruh rangkaian penelitian tindakan kelas (PTK) di SMA Negeri 1 Kabawetan Kabupaten Kepahiang telah dilaksanakan, maka hasil penelitian dapat disimpulkan bahwa dengan model pembelajaran kooperatif tipe Team Games Tournament (TGT), dapat meningkatkan pembelajaran teknik shooting siswa pada permainan sepakbola. Dengan metode ini juga dapat memperbaiki proses pembelajaran. Dengan model pembelajaran ini kemauan siswa akan keberhasilan dalam belajar menjadi 
meningkat, dengan permainan yang menyenangkan berupa game turnamen yang dilakukan membuat siswa merasa senang dan bergairah dalam pembelajaran. Kemudian dengan kreasi dalam pembelajaran dibuat suatu kompetisi memberikan motivasi terhadap siswa untuk menuasai materi pembelajaran dikarenakan akan diberikan suatu penghargaan kelompok yang memenagkan kompetisi.Dari hasil tes awal yang dilaksanakan hingga tes siklus 2 menunjukkan peningkatan, dimana pada tes awal tingkat ketuntasan belajar siswa secara keseluruhan sebesar $40,62 \%$. Pada siklus 1 meningkat menjadi $71,87 \%$ dan pada siklus 2 meningkat menjadi 81,25 $\%$ yangartinya secara keseluruhan nilai siswa sudah mencapai KKM mata pelajaran PJOK di SMA Negeri 1 Kabawetan Kabupaten kepahiang.

\section{Saran}

Dari hasil penelitian ini, peneliti dapat memberikan saran sebagai berikut:

1. Pemberian materi pembelajaran penjaskes di SMA Negeri 1 Kabawetan Kabupaten Kepahiang sebaiknya dikondisikan dengan karakteristik anakanak. Pemeberian motivasi harus dilakukan untuk meningkatkan kemauan belajar siswa.

2. Hasil dari penelitian ini apabila berguna dapat menjadi masukan kepada guru menggunakan model pembelajaran pada penelitian ini untuk meningkatkan keberhasilan siswa dalam pembelajaran PJOK permainan olahraga bola besar.

3. Metode yang digunakan dalam penelitian ini, juga dapat digunakan oleh guru pada mata pelajaran yang lain, sebagai motivasi kemauan belajar siswa agar meningkatkan keberhasilan belajar siswa.
DAFTAR PUSTAKA

ArikKunto, Suharsimi. (2006). Penelitian Tindakan Kelas. Jakarta: Bumi Aksara.

Rosdiani, Dini. (2013). Perencanaan Pembelajaran Dalam Pendidikan Jasmani dan Kesehatan. Bandung: Alfabeta.

Sakun. (2012). Pengantar Pendidikan. Metro: STKIP Dharma Wacana Metro.

Wahyudin, Dinn. (2008). Pengantar Pendidikan. Jakarta: Universitas Terbuka.

Wardhani, Igak. (2008). Penelitian Tindakan Kelas. Jakarta: Universitas Terbuka.

Winarni, Endang W. (2011). Penelitian Pendidikan. Bengkulu: Unit Penerbitan FKIP Universitas Bengkulu. 